\title{
TOUCH SCREEN BASED ORDERING SYSTEM \& DISPLAYING SYSTEM FOR RESTAURANTS
}

\author{
Amar Pai ${ }^{1}$, Deepika Bane ${ }^{2}$, Hardik Rawat ${ }^{3}$, Snehal Patel $^{4}$, Sandhya Kadam ${ }^{5}$ \\ ${ }^{l}$ BE Student, Electronics Department, K.J. Somaiya Institute of Engineering and Information Technology, Mumbai, \\ India \\ ${ }^{2}$ BE Student, Electronics Department, K.J. Somaiya Institute of Engineering and Information Technology, Mumbai, \\ India \\ ${ }^{3}$ BE Student, Electronics Department, K.J. Somaiya Institute of Engineering and Information Technology, Mumbai, \\ India \\ ${ }^{4}$ BE Student, Electronics Department, K.J. Somaiya Institute of Engineering and Information Technology, Mumbai, \\ India \\ ${ }^{5}$ Faculty of Electronics Department, K.J. Somaiya Institute of Engineering and Information Technology, Mumbai, \\ India
}

\begin{abstract}
In this generation, we have advanced in almost all the areas except one field where there is still lack of technology. It is the hotel management system and services and so far there is no step being taken to introduce technology in this area. The above stated project works mainly on the method by which anyone can select any items by their choices which are in the menu display and that order will be sent to the pc of the manager using zig-bee module \& that ordered item will be served to that customer. With the information we have received; we are engaged in an iterative design cycle to develop a final graphical user interface for our touch screen based ordering system \& displaying system.
\end{abstract}

Keywords-Avr16 Microcontroller, Touch screen, LCD display module, Zigbee module $* * *$

\section{INTRODUCTION}

A prototype for customer self-ordering system in restaurants or hotels is developed in this paper. Here, Zigbee is used to transmit the data from transmitter to the receiver. A customer at the table can choose their order with the help of a LCD with touch screen provided. This LCD displays MENU items with their respective cost, so the customer will select one of the item with its picture. When an item is selected, the same data will get displayed on the PC provided at the receiver end. Menu card is displayed at the customer's table. Customer selects various items on the touch screen. The electrical signal is then given to the computer which is controlled by the person in charge or the manager. The manager is able to see the order for which the customer is waiting, he is responsible to order the chefs in charge and hence the order is complete. Once after the food is over, the payment can be done either by the credit card or by cash. This certainly does not require any man power, which overall generates delay in the process.

\section{DRAWBACKS OF EXISTING SYSTEM}

Stress can take place on human finger when used for more than a few minutes at a time. The touch screen can suffer from the problem of fingerprints on the display. The user has to sit closer to the screen as compared to the external keyboard. The screen can be covered more by using hand. It poses a great problem for the people who are illiterate. In previous version the screen used was graphic LCD (GLCD). Major disadvantage of this system was the lack of clarity of screen and the need of photos of the menu or any food item, so in our project we are using color touch screen to increase the graphics and to make it more attractive. Power consumption will be more. Unemployment increases as this reduces the staff workers. There is a possibility of malfunctioning of touch screen and LCD if not properly maintained. Drawback of this system is that it is very costly.

\section{AVR 16 MICROCONTROLLER}

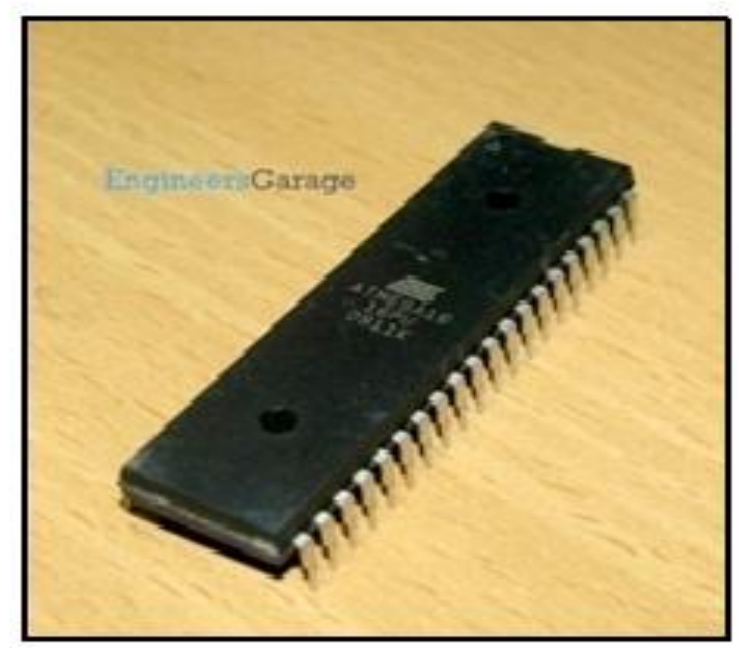


This is the heart of our complete project. It is responsible for all process being executed. It will monitor \& control all the comprising devices or components connected in this unit.

\subsection{Features:}

- $\quad 16 \mathrm{~KB}$ of in system programmable (ISP) flash

- $\quad$ 512B of ISP EEPROM

- $1 \mathrm{~kb}$ of SRAM

- Analog comparator

- Watchdog

- SPI

- $\quad$ 16-bit Timer with extra features

- 4 pulse width modulation

- 8 channel 10-bit ADC

- UART

- 2-wire orientated serial interface

\section{TOUCH SCREEN}

A touch screen is an electronic device consisting of a display that can detect the presence and location of a touch within the display area.

\subsection{Resistive Touch Screen}

Resistive LCD touch screen monitors depend on touch overlay with a flexible top section and a rigid bottom section separated by insulating dots, attached to a touch screen panel.

\subsubsection{Four -Wire Resistive Touch Screen Technology}

In terms on manufacturing \& simplicity four-wire resistive technology is the best. To determine the $\mathrm{x}$ and $\mathrm{y}$ coordinates it uses both the upper and lower sections in the touch screen "sandwich". The primary disadvantage of four-wire technology is that one Coordinate axis (usually the y axis), uses the outer section, the coversheet, as a uniform voltage factor. The constant flexing that occurs on the outer coversheet with use will eventually cause microscopic cracks in the it's coating, due to which it's electrical characteristics (resistance) changes, which degrades the linearity and accuracy of the axis.

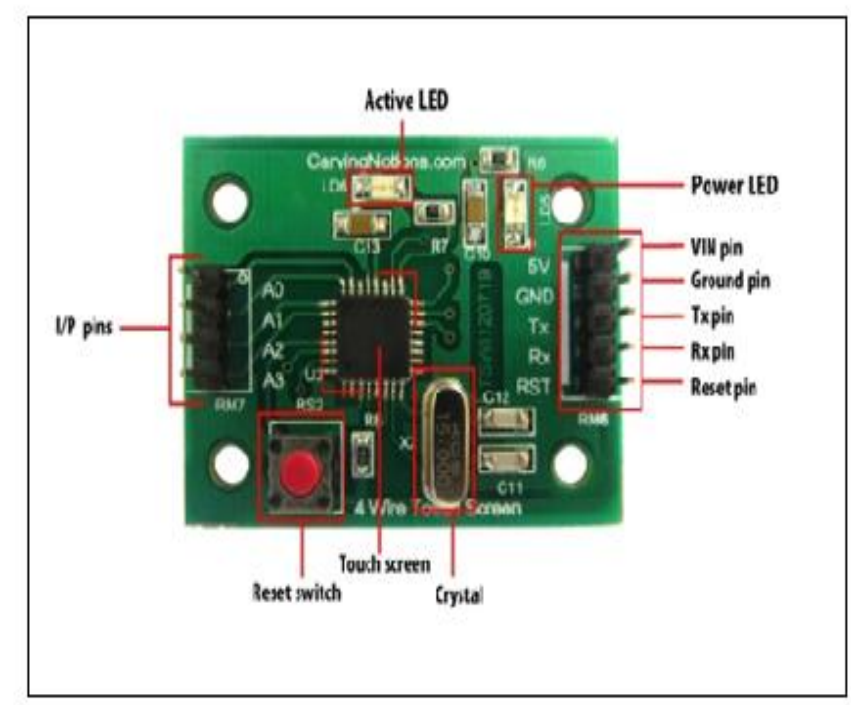

Fig 1 A simple 4-wire touch screen

\section{LCD DISPLAY MODULE}

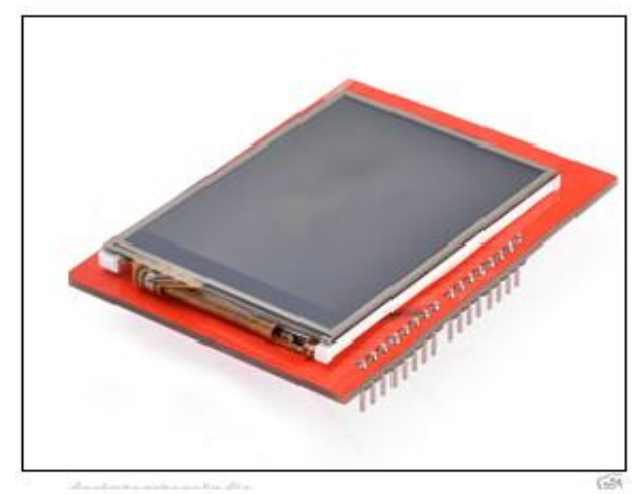

- $\quad 2.4$ inch diagonal LCD TFT display

- $\quad 240$ x 320 resolution- 18-bit $(262,000)$ color

- $\quad 8$-bit digital interface(additional 4 control lines)

- Uses digital pins 5-13 \& analog 0-3.

- $\quad$ Works with Arduino UNO R3

- $\quad 5 \mathrm{~V}$ compatible. Use with $(3.3 \mathrm{~V})$

- $\quad$ Onboard 3.3V at 300mA LDO regulator

- 4 white LED backlight. 4-wire resistive touch screen

\section{ZIGBEE MODULE}

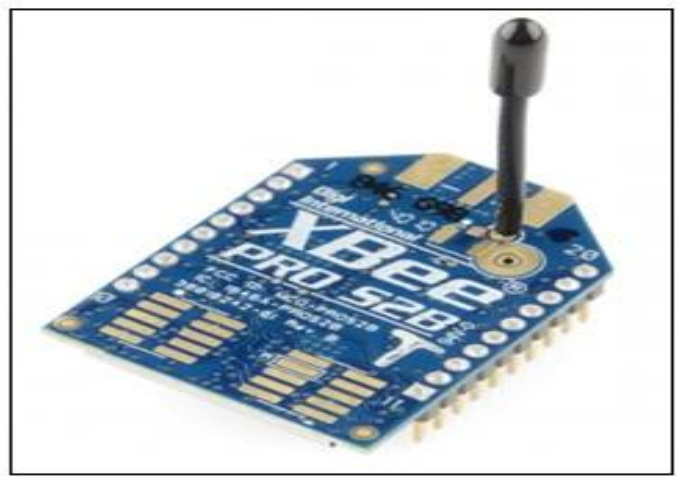


Zig-Bee is a standard that defines a set of communication protocols for low data-rate short-range wireless networking. Zig-Bee based wireless device operates in $868 \mathrm{MHz}, 915$ $\mathrm{MHz}$, and $2.4 \mathrm{GHz}$ frequency bands. The maximum data rate is $250 \mathrm{Kbps}$.

\subsection{Key Specifications:}

- $1200 \mathrm{bps}-1 \mathrm{Mbps}$ interface data rate

- $\quad 2.4 \mathrm{GHz}$ frequency band

- Industrial temperature rating $(-40 \mathrm{C}$ to $85 \mathrm{C})$

- Transmit power $60 \mathrm{~mW}(+18 \mathrm{dBm})$

- Supply voltage: $2.7-3.6 \mathrm{~V}$ DC, transmit current: 205 $\mathrm{mA}$, receive current: $47 \mathrm{~mA}$

- Power-down current $<3.5 \mathrm{uA}$

- $\quad 3.3 \mathrm{~V}$ CMOS UART interface level

\section{ALGORITHM}

1. Initialization of peripheral devices like LCD module \& touch screen

2. Initialization of serial port of UART of microcontroller at $9600 \mathrm{bit} / \mathrm{sec}$.

3. Touch screen\&LCD module with calibration

4. Logical division of touch screen into 9 locations.

5. Wait till user tapping.

6. Get tapping coordinate $\mathrm{X}, \mathrm{Y}$ \& resolve the location we have tapped.

7. Generate a code for command based upon location \& send to serial port.

8. Repeat the above all steps.

\section{FLOWCHART}

\subsection{Transmitter Section}

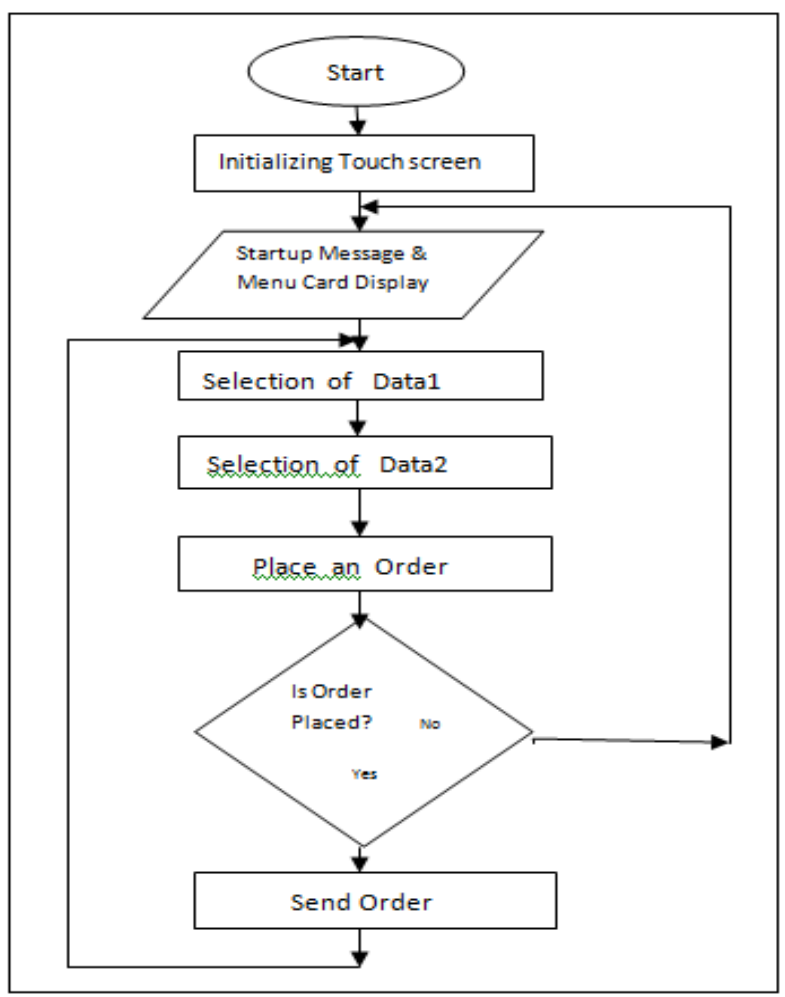

\subsection{Receiver Section}

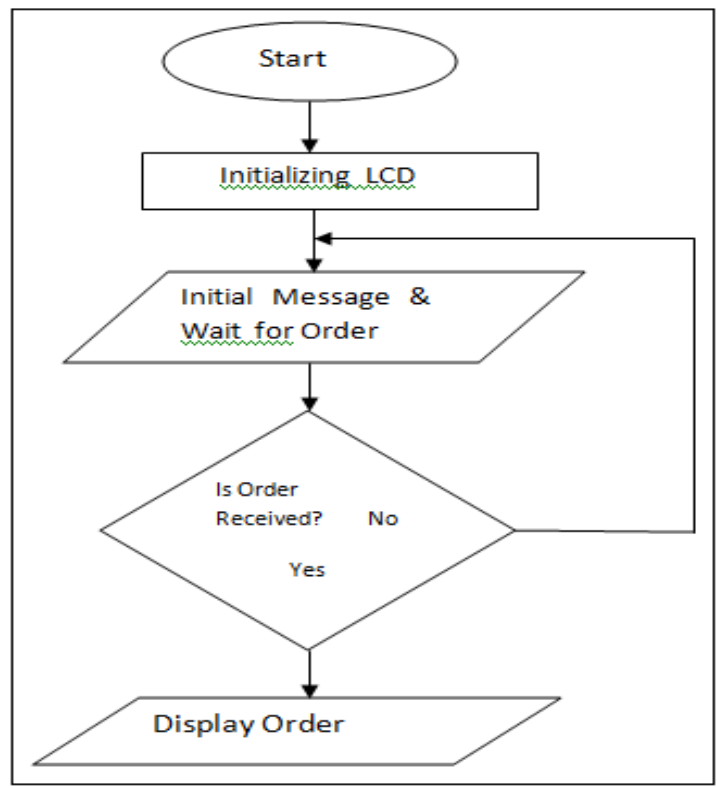

\section{CONCLUSION}

Nowadays, most of the people have enough knowledge about computers, due to which our project can come handy and prove useful for people of all classes because it is simple, fast, and appealing; thus attracting more and more customers. By using such systems at the restaurants, it will be easy and much comfortable to place any kind of order of our choice for both customers' as well as for the management staff. However it will also reduce the number of staff in a hotel; which reduces the cost as well as reduces the mistakes; which can be caused by them. This system will also help the customers to place right order for any kind of cuisine by simply browsing and survey about the various dishes before placing an order and which in turn will help them to have their choice of Food/Dish without having any confusion and can enjoy their meals satisfactorily.

\section{ACKNOWLEDGEMENTS}

We would like to express a gratitude to everyone who gave us the every Possible guidance and help to learn more about TOUCH SCREEN BASED MENU ORDERING SYSTEM \& DISPLAYING SYSTEM FOR RESTAURANTS which imparted more knowledge about the topic. In the first instance we would like to thanks ELECTRONICS department of K.J.SOMAIYA INSTITUTE OF ENGINEERING \& INFORMATION TECHNOLOGY, SION, MUMBAI for giving us permission to commence this project. We would furthermore like to especially thank to Prof. Mrs. Sandhya Kadam for her constant guidance and encouragement who spent long hours on this report in addition to her regular work. The Team also expresses their deep appreciation of the hard work and efficient performance of duties by Head of Department for this project and with her deep knowledge and understanding of the environmental issues, provided guidance at every stage in the course of preparation of this report and her contribution in the exercise is gratefully acknowledged. 


\section{REFERENCES}

[1]. Author Geoff Walker, Fundamentals of Touch Technologies Revised Edition (6/3/2012)-IEEE

[2]. A.H.G Al-Dhaher, "Integrating hardware -and software for the development of- Microcontroller based systems", Microprocessors and Microsystems, Vol. 25, Issue 7, October 2001, Pp. 317-328.

[3]. Hamit E, "Implementation of software- based sensor linearization algorithms on -low cost microcontrollers", ISA Transactions, Vol.49, Issue 4, October 2010, Pp. 552-558.

[4]. Stanislav Safaric, Kresimir Malaric, ZigBee wireless standard.

[5]. B. Stumpe, "Experiments to find -a manufacturing process for an $\mathrm{x}-\mathrm{y}$ touch screen", CERN.

[6]. XBEE Module datasheet

(http://www.datasheetcatalog.com/datasheets_pdf)

[7]. Lee, S.K; Buxton, William; Smith, K.C; "A multi-touch three dimensional touch- sensitive tablet,", CHI '85; Volume 16, Issue 4, pp 21-25

[8]. ATMEL Corporation.16-bit AVR Microcontroller with 16/32/64 kb ATMEGA644PV ISP flash data sheet

[9]. Author Scott Edwards(2003), Basics of LCD Electronics Corporation Ltd. 